\title{
Sobre a saúde de quem trabalha em saúde: revendo afinidades entre a psicodinâmica do trabalho e a saúde coletiva
}

\author{
On the health of those who work in health: reviewing affinities \\ between work psychodynamics and collective health
}

Giovanni Gurgel Aciole1 , Márcia João Pedro'

DOI: 10.1590/0103-1104201912015

RESUMO O trabalho em saúde está atravessado pela intensa dinâmica entre intenções e gestos, no seio da qual a construção do Sistema Único de Saúde agudiza questões relativas ao uso da força de trabalho e seu desgaste, ensejando o debate e a reflexão sobre a saúde de quem cuida da saúde. À guisa de ensaio sobre essa questão, este estudo envereda pelo campo discursivo das práticas de cuidado e da gestão do trabalho em saúde, buscando identificar convergências e aproximações entre a teoria da 'psicodinâmica do trabalho', que preconiza a centralidade da subjetividade dos trabalhadores, e as propostas da saúde coletiva brasileira sobre o trabalho em saúde e a produção do cuidado integral e humanizado.

PALAVRAS-CHAVE Trabalhador da saúde. Saúde do trabalhador. Atenção integral à saúde. Gestão em saúde. Saúde pública.

ABSTRACT The work in health is crossed by the intense dynamics between intentions and gestures, within which the construction of the Unified Health System aggravates questions regarding the use of the work force and its wear, giving rise to the debate and the reflection on the health of those who take care of health. By way of essay on this matter, this study goes down the road of the discursive field of health practices and management of health work, in order to identify the convergences and approximations between the theory of work psychodynamics, which advocates the centrality of the subjectivity of workers, and the Brazilian collective health proposals on the work in health and the production of integral and humanized care.

KEYWORDS Health personnel. Occupational health. Comprehensive health care. Health management. Public health. 


\section{Introdução}

Em sua crítica ao capital, Karl Marx ${ }^{\mathbf{1}}$ apontou a sinergia dos métodos para aumentar a produtividade do trabalho, que utilizam os meios existentes no domínio e na exploração da força de trabalho e degradam o trabalhador até o apêndice de uma máquina, alienando seu potencial intelectual. Pari passu, a incorporação dos métodos e técnicas é saudada como poder independente.

A saúde, vista como setor produtivo, sofre a influência das organizações hegemônicas e dos interesses do capitalismo, o que coloca seus trabalhadores nesse processo de degradação alienante ${ }^{2-4}$. Parte do trabalho de saúde é meio para a recuperação da força de trabalho, produzindo nos que o fazem a alienação e a submissão ao poder da ciência e da técnica, significada como biopolítica de controle da saúde corporal e dos mecanismos de recuperação da força laboral, em que opera a medicalização da vida, sob a ótica do corpo humano tomado como máquina ${ }^{5}$. Sob esse enfoque medicalizador, saúde e doença são objetos dotados de características quantificáveis; passíveis de técnicas e instrumentos produzidos em ambientes específicos, por saberes hierarquizados e ambientes funcionalizados segundo densidade tecnológica e de produção de procedimentos, sob a centralidade da 'organização' científica do trabalho, isto é, um trabalho em saúde extremamente poroso ao (re)desenho dos processos produtivos que se sucedem no capitalismo.

O movimento sanitário brasileiro busca inverter a lógica dessas práticas para sua antípoda, formando unidades de saúde e equipes multiprofissionais, que compartilha produção de atos e divide responsabilidades e saberes; aloja-se na abertura para a comunidade como espaço contraditório do fenômeno saúde/ doença no contexto social e econômico de sociedades desiguais; e se agrega no desafio ético-político de calcar o trabalho em saúde sob o manto da humanização das práticas e do cuidado integral da saúde como direito de cidadania. Desafios que impõem a mobilização de recursos e arranjos institucionais, reformulação de serviços e ações, ampliando seu escopo e sua integralidade, e na criação de um sistema de saúde fundado na democratização institucional e política e na modernização da gestão e dos modelos de atenção à saúde 2,6-10.

Importa, pois, a preocupação com como a saúde dos que trabalham com saúde é afetada pela organização de suas práticas, pela gestão dessas organizações e pelo próprio trabalho em si, marcado com as características aqui apontadas? E de que maneira, com que recursos e atitudes lidam com elas? Como pensar concretamente em desenvolver trabalho em equipe, com relações mais horizontalizadas, múltiplas atividades, qualificação dos saberes sem o atendimento das necessidades básicas dos trabalhadores (como salário digno, vínculos empregatícios estáveis e relações contratuais seguras) e sem as condições de desempenho das funções compatíveis com a responsabilização que lhes é conferida?

Abre-se aqui uma discussão que questione posições estruturalistas, funcionalistas e/ou economicistas sobre o mundo do trabalho em saúde e a sua gestão. Isso significa refletir sobre o que constitui a própria identidade do saber-fazer em saúde e a saúde dos que trabalham em saúde. Abertura que necessita trilhar caminhos de identificação entre campos teóricos afins. Para tanto, este estudo se mune do conceito de 'afinidades eletivas', conforme o significado adotado por Max Weber"11. Instigase pela leitura de Michel Lowy ${ }^{12}$ sobre os usos da expressão e do seu valor sociológico, em que destaca a dimensão de afinidade, que, segundo ele, refere-se menos a uma relação causal e mais ao parentesco espiritual, à congruência e à adequação interna, isto é, cria a possibilidade, mas não a necessidade de convergência ativa, de atração eletiva. A transformação dessa potência em ato, a dinamização da analogia, depende de condições históricas e sociais concretas. Condições cuja existência é vislumbrada nas formulações teórico-conceituais que animam a saúde coletiva e a teoria da psicodinâmica do trabalho. 


\section{A constituição do campo discursivo da saúde coletiva sobre o trabalho em saúde}

A respeito das concepções da saúde coletiva brasileira sobre o trabalho em saúde, partir-se-á da proposição seminal de Mendes-Gonçalves ${ }^{13}$, que ampliou a noção de tecnologia para além da dimensão máquina/equipamento, reconhecendo existir no processo de trabalho em saúde a presença de instrumentos materiais (como medicamentos, equipamentos, insumos, instalações físicas e infraestruturais) e não materiais (os saberes que articulam os agentes e as práticas desse processo), numa dinâmica entre objeto, instrumentos materiais e atividade, cuja principal ferramenta seria de natureza intelectual, imaterial.

Predomínio intelectual, imaterial, ampliado por Emerson Merhy $^{2}$ com a construção de uma tipologia de tecnologias envolvidas nesse tipo de trabalho: leves, leve/duras e duras. As leves seriam atuantes nas relações implícitas no cuidado em saúde; as segundas seriam os saberes estruturados, ou seja, teorias e técnicas; e as últimas seriam os recursos materiais/ equipamentos necessários para determinados procedimentos. E que afiança a natureza produtiva do setor saúde como fortemente articulada a territórios tecnológicos não materiais, no reconhecimento da centralidade que o trabalho vivo, criado e executado em ato, ocupa nos processos produtivos do setor.

Realizando uma investigação sobre o trabalho da enfermagem, Pires $^{3}$, por exemplo, pode construir algumas noções sobre o trabalho em saúde nas organizações, o qual, além de suas especificidades, caracteriza-se por: a) manter características do tipo trabalho artesanal; b) ser um trabalho institucionalizado, realizado por equipe multiprofissional, cujo elemento central é o médico, que decide o diagnóstico, os exames complementares, a terapêutica e o uso, ou não, de equipamentos e delega tarefas a outros profissionais de saúde, que disso dependem para que seu trabalho se realize; c) produzir assistência fragmentada, resultante desse trabalho parcelado e compartimentado.

Nas tentativas de ruptura com a fragmentação do trabalho, pode-se reconhecer uma agenda muito ativa e propositiva de novos modelos de atenção à saúde, tanto da gestão organizacional quanto do trabalho em saúde, indicando uma intenção de se libertar dos modelos hegemônicos neoliberais, hoje ainda vigentes nos modos de produzir o trabalho em saúde. O convite reformista se anuncia, por exemplo, com a proposta da ampliação da clínica $^{\mathbf{1 4}}$; na construção de outra relação dialógica entre trabalhadores e usuários ${ }^{15}$; e na produção de vínculo com acolhimento e resolutividade ${ }^{\mathbf{1 6}}$; no reconhecimento de que todos os trabalhadores fazem clínica e são aptos a produzir atos de produção de saúde, centrados em tecnologias relacionais, tendo o cuidado como doador do sentido e do significado da clínica, ou como 'alma' dos serviços, para a qual se propõe uma caixa de ferramentas multidimensionais para a sua produção ${ }^{2,17}$. São contribuições de profundo valor ético/estético para as políticas de saúde, pois contribuem para a definição de um valor de uso para a vida, ao defenderem a preservação da capacidade criativa e o agir autônomo dos trabalhadores em sua plena subjetivação, apesar dos constrangimentos gerenciais e organizacionais dos poderes a que estão submetidos.

O trabalho em saúde vem sendo posicionado como integração das disciplinas e das profissões, de forma a dar conta da nova concepção biopsicossocial do processo de saúde/ doença e do desenvolvimento das práticas de saúde. Trabalhar em equipe de forma interdisciplinar se mostra fundamental para a transformação dos processos de trabalho em saúde, considerando os desafios originários das três vertentes com que é saudada a 'integralidade'18, que assumiu a força de uma dimensão constitutiva da atenção da saúde, orientada por políticas e ações programáticas voltadas a atender às necessidades de saúde do usuário individual e coletivo, considerando as dimensões biológicas, culturais e sociais. 
Quando qualquer dessas vertentes não é atendida, pode haver um trabalho descontínuo e fragmentado. Portanto, ele deve ser alcançado por arranjos singulares que garantam o cumprimento de três critérios balizadores, a saber: capacidade de produzir saúde do serviço ou da equipe na forma de pactos e arranjos de projetos terapêuticos construídos solidariamente; viabilidade técnica, financeira e política dos projetos ou arranjos acordados; articulação de projetos, desejos e projeção de necessidades à realidade ${ }^{9,17}$. Dever-se-ia considerar, também, a realização profissional e financeira dos trabalhadores de saúde, que fica obscurecida pela sobrevalorização dos aspectos que colonizam o campo das práticas de saúde, em termos de custos/benefícios, e da tríade eficácia, eficiência e efetividade, simplificados pelas óticas economicistas e produtivistas ${ }^{19}$.

\section{O trabalho em saúde e as novas dimensões ético- políticas em que se move a produção do cuidado}

Duas consequências lógicas se apresentam na abordagem da saúde como um produto de tecnologias, em que predominam usos e utilidades da sua forma dura. Primeiro, o fato de que, subsumidas nessa racionalidade constitutiva, as práticas de saúde caminham para uma feição desumanizada, para os que dela se servem, e desumanizadora dos que a praticam. Essa premissa lógica traz como resposta a afirmativa de que é preciso imprimir-lhes um valor humanizador, de modo a torná-las menos frias e utilitárias, menos fragmentadas e mais integrais. Do mesmo modo, porque imprimem essa racionalidade tecnológica ao processo de formação da força de trabalho. Os agentes das práticas de saúde seguem sendo formados num processo inadequado para lidar com o elemento subjetivo e humanista presente nas suas relações.

Consequências lógicas que levam a duas políticas: a que busca corrigir essa formação imperfeita nos caminhos de uma Educação Permanente em Saúde (EPS), que contorna os efeitos alienantes que o trabalho em saúde de feições tecnicistas imprime às relações pessoais/profissionais no trabalho, além de diminuir o fosso entre as intenções das políticas e a operacionalização das práticas de saúde nos horizontes do novo trabalho ${ }^{20}$; e outra, de medidas para sanar os deficits humanísticos tanto de profissionais quanto de usuários, resgatando-lhes o potencial libertador da desalienação subjetivadora ${ }^{19}$.

A integralidade desafia a saber 'o que' e ‘como’ fazer em saúde, para responder às necessidades de cada um. A produção do cuidado, vista como uma dimensão essencial do agir em saúde, provoca alterações nos processos de trabalho ao demandar uma práxis capaz de negociar e responder às necessidades dos usuários, o que significa intervir num projeto de vida, de construção de identidade, confiança e responsabilidade ${ }^{19}$.

A autonomia confere aos agentes que vivenciam no trabalho uma responsabilidade social e um engajamento que deve ir além do simples executar de tarefas. Ela se irradiaria para o campo social, cultural, político e para a subjetividade de cada um que participa dessa relação, usuário e trabalhador da saúde, pois agir em direção à universalidade impulsionaria a construir o acesso para todos, porém, equacionado pela régua da equidade, o que exige pactuar com todos o que cada um necessita, o que induz ao aumento de responsabilidade, via envolvimento genuíno, para que aumente a eficácia do seu trabalho ${ }^{14,17,19}$.

O resgate ou a produção da subjetividade obrigaria que os serviços de saúde se constituíssem em espaços onde os trabalhadores possam ser sujeitos de sua própria existência. Os temas da obra e da sobrevivência, articulados. Seja porque a subjetividade depende da abertura dos sujeitos para novos referenciais, ainda que seja tarefa difícil despertar a pessoa para a necessidade de conhecer novos mundos, quando se pretende a criação de novas instituições, novas políticas e novos profissionais ${ }^{21,22}$; 
seja porque a atenção integral à saúde exige de seus agentes uma competente capacidade operacional para implementar um modo de produzir saúde coerente com as diretrizes assumidas, isto é, que o cuidado seja marcado pelo direito universal de cidadania e que as organizações de saúde sejam gerenciadas numa conformação coletiva, com processos de trabalho compartilhados em equipe ${ }^{4}$, mesmo que a ampliação dos objetos de intervenção, a introdução de novos instrumentos de intervenção e tecnologias continuem a mobilizar saberes e modos específicos do ser profissional ${ }^{\mathbf{2}, \mathbf{4}}$.

Produzir trabalho com integralidade implica, portanto, um agir conjugado entre profissionais e suas diversas formas de saber com e nos serviços de saúde, em que a relação profissional saúde-usuário é chave para a reconstrução da ética, da política e das técnicas de cuidado da saúde, sempre mais e mais promotora de qualidade de vida $\mathbf{2 1 , 2 2}^{\mathbf{2 2}}$

Um convite à felicidade permearia, por fim, o cotidiano do trabalho: um convite, porém, difícil de incorporar, expressar e assimilar. A realidade dos usuários e profissionais difere significativamente quando se considera a subjetividade humana, sendo necessárias estratégias e ações diferenciadas a cada dia, a cada pessoa, a cada situação que se apresenta a esses profissionais de saúde. Abrir-se-ia, todavia, a possibilidade de identificação e análise dos mecanismos, conscientes e/ou inconscientes, ativos e/ou passivos, como que os trabalhadores estabelecem para preservar, retardar ou minorar os efeitos decorrentes de sua prática cotidiana. Nenhuma palavra, até o momento, foi dita sobre como as diferentes realidades de trabalho impõem um desafio pungente: lidar com o sofrimento alheio e, ao se afetar por ele, descobrir com que dispositivos éticos, técnicos e políticos específicos lidar com o seu próprio. Trata-se, portanto, de inquirir sobre como se cuidam os produtores do cuidado, o que implica buscar possibilidades analíticas de interferir na dinâmica cotidiana em que isso acontece.

A atitude 'cuidadora' precisa se expandir para a totalidade das reflexões e intervenções no campo da saúde, de modo a considerar tanto o agente cuidador quanto o sujeito do cuidado. Para que se interrogue: como, naquele encontro de sujeitos no e pelo ato de cuidar, aparecem os projetos de felicidade, de sucesso prático de quem quer ser cuidado? Ou sobre o papel que têm desempenhado aqueles que querem ser cuidadores, nas possibilidades de conceber essa felicidade, em termos de saúde. Que lugar podem ocupar na construção desses projetos de felicidade que estariam ajudando a conceber ${ }^{19}$ ? A questão central parece ser: como pensar possível integralizar o cuidado sem integralizar a ação dos agentes desse cuidado? E, ainda: como desconsiderar esse sujeito em sua identidade, carregada de expectativas, desejos, conflitos, entre outros fatores subjetivos?

Quando se pensa em humanização como política, porém, talvez acabe-se emprestando à humanização um significado de sintoma, onde essas medidas políticas refletiriam a tendência do sistema de saúde de desvalorizar o ser humano, e pode-se entendê-la como uma receita aos trabalhadores de saúde para adotarem posturas e comportamentos cuidadores. Não se estaria, mais uma vez, moldando os trabalhadores às medidas vindas do alto (gestão) para baixo (trabalhadores), como supremo objetivo da produção do trabalho ${ }^{21}$ ? Seria, de fato, medida necessária, considerando a lógica dominante do esquecimento das pessoas, com medidas econômicas que visam ao crescimento e à estabilidade monetária, e não necessariamente à melhoria das condições de vida das pessoas?

Em que pesem as lacunas existentes entre intenção e gesto, essas novas exigências para os profissionais de saúde implicam transformar os métodos, papéis, responsabilidades, desempenho e a relação com equipe e usuários, adquirir novos conhecimentos e, principalmente, a necessidade de adaptar essa perspectiva inovadora à complexidade que há no processo de trabalho em saúde, assumindo outras dimensões de análise e intervenção. Isto é, precisa-se de um 'novo' trabalhador da saúde. 
A política de EPS aposta, por sua vez, no resgate da sensibilização subjetiva e na produção de consciência crítico-reflexiva do trabalhador e do gestor, considerando esse resgate e essa produção como condições imanentes do trabalho em saúde, para expandir e viver novos horizontes, o que a torna tarefa complexa e difícil. Essa EPS implicaria, afinal, modificar ações e formar perfis profissionais, exigindo um trabalho de autoanálise e autogestão, envolvendo pensamento e afetividade ${ }^{20}$. Tal aposta faz com que a EPS deva apresentar algumas características marcadoras: maior porosidade à realidade mutável e mutante das ações e dos serviços de saúde; forte ligação política com a formação de perfis profissionais e de serviços; introdução de mecanismos, espaços e temas que geram autoanálise, autogestão, implicação; mudança institucional; ruptura com instituídos, fórmulas ou modelos; e experimentação, em contexto, em afetividade - sendo afetado pela realidade/afecção, numa espécie da causação circular com maior porosidade 20 .

O que se encontra, ainda, é uma educação profissional continuada voltada ao desenvolvimento do trabalho em suas características práticas e na qualidade do cuidado ao usuário, em detrimento do sofrimento e das dificuldades vividas pelos profissionais em suas vivências diárias e particulares de angústia. Afinal, as injunções dos ajustes fiscais macroeconômicos e de estabilização monetária sempre presentes continuam a contingenciar recursos financeiros e ameaçam a sustentabilidade das políticas universalistas, em franco conflito com o movimento de expansão e afirmação de direitos sociais, deteriorando ou contingenciando recursos materiais e humanos e retardando a consolidação e a promoção da inclusão social desejada.

Seja pela excessiva burocratização, seja pelos limites transformadores de um trabalho marcado por precarizações e injunções utilitaristas e privatistas de várias ordens, o fato é que as propostas de humanização e educação permanente correm o risco de ser reduzidas, pela razão instrumental, a instrumentos da gestão e dispositivos da biopolítica, abrindo notáveis flancos nos seus potenciais transformadores, quedando impotentes diante do instituído 23.

As reflexões aqui apontadas indicam a necessidade de aprofundar o diálogo entre as práticas de produção do cuidado e as práticas de gestão dos trabalhadores, na perspectiva de compreender e analisar a constitutividade que subsuma agentes e pacientes na produção de saúde. E de pensar em como os dispositivos de 'humanização' e 'educação permanente' têm funcionado, de forma a permitir a participação dos trabalhadores. O quanto existe de participação efetiva e real do trabalhador de saúde que atua em contato direto com o usuário na criação e na inovação desses modelos e propostas? Outros aportes teórico-conceituais podem operar sinergicamente na direção da desalienação e do resgate humanista pretendido.

\section{A saúde de quem trabalha em saúde: afinidades eletivas entre a psicodinâmica do trabalho e a saúde coletiva}

No momento atual, detecta-se um descompasso entre as exigências da gestão, que mantêm seu foco nos resultados e custos, e a produção do cuidado dos usuários com integralidade e humanização, que exige desenvolvimento do profissional enquanto cuidador, responsável, consciente, eticamente implicado, tecnicamente habilitado, politicamente atuante e socialmente comprometido. Características que invocam a participação mais ampla da subjetividade, enquanto tem-se um trabalhador precarizado em seus direitos e suas necessidades.

Esse descompasso potencializa dificuldades no engajamento com essas práticas, potencializando vivências de sofrimento no trabalho. Ou seja, convive-se com propostas de políticas impregnadas de intenções norteadas 
ao desenvolvimento integral e realizador de cuidado do trabalhador, enquanto se aprofundam práticas de gestão que conformam realidades intangíveis à sua efetivação ${ }^{\mathbf{2 4}}$. Fato que cria o hiato entre o real e o prescrito, por exemplo, na atual Política Nacional de Saúde do Trabalhador ${ }^{25}$.

Para uma aproximação efetiva das relações de trabalho em saúde e saúde do trabalhador que ora se percorrem neste estudo, deve-se voltar para a chamada psicodinâmica do trabalho - formulada por Christophe Dejours ${ }^{26}$ -, por duas razões de eleição. Primeiro, ao propor o abandono do uso de Psicopatologia do Trabalho, na década de 1980, argumentando não existir correlação de causalidade entre doença mental e organização do trabalho. E, segundo, ao apontar a normalidade como maior enigma para a abordagem da relação homem/trabalho, abrindo perspectiva para o estudo do sofrimento, mas, também, do prazer e da capacidade do trabalhador de enfrentar a realidade através de estratégias defensivas para alcançar o equilíbrio psíquico. Ao adotar esse olhar mais dinâmico para o que chamou de psicodinâmica do trabalho, compôs necessariamente uma clínica, que envolve método, pesquisa e ação, com objetivo de apropriar-se da dimensão sociopsíquica do trabalho. Essas propostas remetem por afinidade à eleição de dois enfoques que dialogam com a saúde coletiva.

Em primeiro lugar, trata-se de um conjunto teórico e metodológico que estuda de forma inovadora a inter-relação homem/trabalho nas contradições do modo de produção capitalista; em segundo lugar, ao embasar seu objeto de estudo na dinâmica da relação entre organização do trabalho e processos de subjetivação, que se manifestam através de vivências prazerosas ou de sofrimento e em estratégias que permitam mediar as contradições dos contextos de trabalho, nas patologias sociais, na saúde e na doença ${ }^{27}$, muito embora se diferencie dos tradicionais estudos de psicopatologia do trabalho. Ao centrar o entendimento e a significação do sofrimento na escuta do trabalhador e na utilização de sua fala como instrumento de pesquisa e intervenção ${ }^{\mathbf{2 8}}$, revela um arcabouço teórico em que se visualizam confluências com as propostas dos reformuladores dos processos de trabalho em saúde coletiva, conforme vem-se sumarizando.

Com essas razões substanciais, contribui para desvendar a repercussão das organizações de trabalho sobre o aparelho psíquico, posto que privilegia o estudo da normalidade sobre a patologia no trabalho, na busca do entendimento da dinâmica que promove o equilíbrio entre os trabalhadores mesmo quando estão submetidos a situações de trabalho desestruturantes, produtoras de sofrimento ou desconforto. O sofrimento tem sua origem não do exterior, como algo vindo 'de fora', mas nas relações estabelecidas pelo trabalhador com a realidade externa, pelo fato de que sua estrutura pulsional com relação ao meio pode conduzir a uma representação penosa da realidade do trabalho, conforme ele atenda ou não à satisfação dos desejos inconscientes ou pulsionais existentes no interior de cada trabalhador, em sua precípua natureza humana.

O prazer ou o sofrimento no trabalho - definido como atividade coordenada desenvolvida por homens e mulheres para realizar uma tarefa utilitária - não é produto da execução estrita da organização prescrita, mas das relações subjetivas, das condutas e ações dos trabalhadores, autorizadas pela organização do trabalho na qual se inserem ${ }^{28-30}$. O sofrimento vivido no trabalho seria, portanto, um espaço clínico intermediário na luta entre o funcionamento psíquico e mecanismos de defesa frente a pressões organizacionais desestabilizantes ${ }^{30}$.

A produção de atos de saúde, por exemplo, submetida a uma organização cuja 'utilidade' encontra-se marcada pelos vetores ético-políticos do cuidado humanizado e integral, coloca exigências que vão além da preocupação em desenvolver uma ação eficaz. Precisa ser, concomitantemente, um trabalho cujas características qualitativas são o alinhamento com as vertentes conceituais da saúde e dos princípios constitucionais do SUS. Existem preocupações locais territorializadas e singulares, bem 
como aspectos psicológicos e práticas que demandam engajamento e ações que não se encontram preconizadas pelos prescritos e acarretam vivências emocionais que podem ser de sofrimento.

Todas essas considerações convergem pelo fato de que o trabalho se caracteriza por um enquadramento social de obrigações e de exigências. Situado frente à prescrição de uma tarefa dada, e por realizar, implica um consumo/ utilização de técnica, por sua vez, conformada na tríade comum da eficácia/eficiência/efetividade. No cenário da saúde, essa vertente se encontra acentuada pelo ambiente complexo e pela própria especificidade do trabalho, das políticas, dos modelos e do cuidado: contexto de ideias complexas e de materialidade sempre imprevisível. Campos ${ }^{\mathbf{2 1}, \mathbf{2 2}}$ argumenta sobre essa imprevisibilidade, apontando as regularidades existentes no trabalho em saúde, cercado por padrões e protocolos, mas no qual mesmo as situações já conhecidas, como doenças já identificadas, manifestam-se com diversidade a cada vez.

Ao dar ênfase à singularidade da clínica, cujo senso comum é a afirmação de que 'cada caso é um caso', a proposta da clínica ampliada advoga que o profissional atue com criatividade e iniciativa frente a tal fato ${ }^{14}$ e é um claro convite afirmativo da singularidade subjetiva que o marca em sua especificidade. Carrega junto o trabalhador como ser dotado de uma singular subjetividade, o que marca, a nosso ver, uma forte afinidade eletiva com a teoria da psicodinâmica do trabalho. A presença do elemento humano na realização da tarefa outorga a este trabalho uma complexidade enorme, pois essa ‘dimensão’ representa justamente aquilo que será reajustado, rearranjado, imaginado, inventado, acrescentado. Por isso, a tarefa em si nunca atingirá de forma rigorosa $o$ prescrito, porque o real incide sobre a dimensão humana do trabalho. É aquilo que se deve ao homem na realidade dada pelo trabalho ${ }^{30}$.

Para driblar as situações que fogem ao prescrito, os processos de trabalho supõem um engajamento e a participação da 'inteligência prática', que seria a inteligência mobilizada na situação real de trabalho ${ }^{31}$. Peduzzi e Schraiber ${ }^{32}$ reconhecem esse engajamento ao dicionarizarem que o entendimento do contexto do trabalho em saúde somente é possível na presença de seus agentes: os trabalhadores. Afinal, a realidade destaca-se como objeto de trabalho somente quando o sujeito assim o delimita. O espaço vivencial e real do trabalho é recortado pelo olhar do sujeito, que contém um projeto prévio de alcançar o produto desejado. O que está na mente do trabalhador é que transformará o objeto em produto.

Objeto e instrumentos se configuram, enfim, pela presença desse agente que lhes imprime uma dada finalidade, com projetos individuais e coletivos ${ }^{8-10}$. Essa presença/participação se torna fonte de prazer quando permite emergir uma identidade, bem como a possibilidade de criar, inovar. Para que esse prazer se realize, há a necessidade de um espaço de liberdade onde o trabalhador possa se expressar com autonomia. Ter autonomia suscita a possibilidade de um investimento subjetivo na atividade de trabalho. Mais que isso, ter liberdade de criar permite o encontro de mobilizações subjetivas para o enfrentamento do sofrimento no trabalho ${ }^{27}$.

A mobilização subjetiva seria o processo realizado através do uso da inteligência prática e pelo espaço público de discussão sobre o trabalho, em vias de ressignificar e transformar as situações de sofrimento. É uma ação que visa a equacionar o conflito entre o que é imposto pela organização do trabalho e as necessidades psíquicas do trabalhador. Seria uma forma de resistir ao que se encontra prescrito para dar conta do real ${ }^{29}$.

Na mesma direção, a psicodinâmica do trabalho propõe uma organização do trabalho que considera essa dimensão coletiva do trabalho e afirma que, para haver prazer no ambiente laboral, é necessário que a organização ofereça condições ao trabalhador de desenvolver três importantes ações, sejam elas: mobilização de inteligência prática, espaço público de discussão e de cooperação. Ênfase no coletivo, que é o cerne do que vem propondo Campos, 21,22, 
quando afirma que concentrar o profissional da saúde em apenas uma etapa parcelar do projeto terapêutico produz alienação; e deixar de envolver esses sujeitos no projeto coletivo do cuidado limitará a possibilidade de desenvolver elementos potencialmente estimuladores de sua criatividade e levará à perda da responsabilização pela promoção da saúde e da recuperação do paciente. Por outro lado, são coletivos que requerem cooperação, solidariedade e reconhecimento entre os trabalhadores e de um espaço constituído onde possam se expressar, ouvir, relacionar-se e produzir com equidade de saberes e poderes.

A configuração de coletivo assim formado fortalece o indivíduo, pois cria um poder de negociação de suas demandas e um apoio social ${ }^{33}$. Necessidade que advoga encontrar eco e apoio da gestão, cujo modo de ser estimule essa iniciativa nos trabalhadores, dado que as instituições sairiam do jugo de corporações profissionais. Tais aspectos do horizonte da gestão e seu entrelaçamento com o estímulo à autonomia do trabalho talvez sejam uma grande questão que ainda se coloque: em que medida as instituições de saúde podem e devem funcionar no apoio e na indução da autonomia?

Um desafio que ainda não se conseguiu superar é justamente conciliar essas duas vertentes, liberdade/controle e autonomia/ responsabilidade, que se apresentam, em síntese, contraditórias. Afinal, ainda não foram vislumbradas possibilidades de operar os sistemas de saúde sem certo controle institucional, dado pelas disputas de poder, burocratização do serviço público, corporativismos, entre outras situações que implicam certo abuso do sistema e que necessitam de um freio $9,22,23$. Na convivência do coletivo, fazem-se acordos estabelecidos através de normativas e formas de regras de trabalho que estão vetorizadas, de um lado, por um objetivo de eficácia e de qualidade de trabalho; e, por outro, por um objetivo social. O compromisso que se firma é, a um só tempo, técnico e social: dobra que estabelece a vinculação dialética entre prazer e sofrimento, que devem ser revelados em sua dupla não simultaneidade ${ }^{34}$.

A psicodinâmica do trabalho é pensada e proposta como uma clínica que tem como objetivo promover espaços coletivos de discussão onde o trabalhador possa elaborar e (re)significar o sofrimento vivido em todos os seus vetores, seja relacionado à organização do trabalho, aos aspectos relacionais do convívio, às vivencias subjetivas, onde ele possa resgatar o sentir, o pensar, o julgar e o agir de forma livre, construindo novos sentidos ao vivido ${ }^{35}$. O desafio da clínica do trabalho é, diante das diferentes práticas relacionadas, criar dispositivos técnicos, éticos e políticos considerando os princípios e o propósito da análise da dinâmica entre a organização do trabalho, o sofrimento e a saúde mental do trabalhador ${ }^{36}$.

O método da roda ${ }^{21}$ coloca o aumento da fruição de prazer que uma gestão compartilhada ofereceria ao trabalhador, na oportunidade de participar de decisões e nos espaços institucionais onde todos podem participar de processos criativos. A produção do trabalho, visto como Obra (Opus), permitiria relações mais afetivas e prazerosas com o trabalho, embora não se elimine a parte árdua e penosa do trabalho. Mas dessa forma se produz um trabalho coletivo que carrega a contribuição das singularidades de cada sujeito envolvido nesse processo. A clínica do trabalho compartilha desse enredamento na análise do desejo do coletivo, a partir da qual orienta o grupo para mudanças da situação vivida e para a ressignificação das vivências. É importante que a demanda aflore do próprio grupo e que o trabalhador não seja simplesmente ouvido, mas que haja escuta, ou seja, uma compreensão do discurso, pois a experiência real de trabalho muitas vezes se localiza na fronteira entre o discurso e a resistência ao mundo real, tornando-se obscura na própria consciência do indivíduo. O ofício e o saber fazer muitas vezes ignoram a si mesmo e necessitam de um outro para que possam ocorrer a descoberta e a aprendizagem ${ }^{37}$. 
A clínica do trabalho busca compreender a dinâmica da organização do trabalho e do próprio trabalho, em que os aspectos subjetivos do trabalhador entrem em pauta e possam ser trabalhados; e propõe enfocar não apenas a demanda de humanização preconizada e instaurada politicamente por determinação da gestão, mas as demandas coletivas dos grupos de trabalho em questões vividas em seu cotidiano que possam estar ligadas ao modo como estes promovem a saúde e o bem-estar dos trabalhadores. Incluir seus pressupostos em cada contexto específico permite evidenciar demandas dos coletivos que quase nunca vêm à tona, submersas à eficiência ou eficácia do trabalho, e ecoam expectativas e necessidades dos trabalhadores quanto ao desenvolvimento individual e coletivo de seu contexto específico.

A psicodinâmica do Trabalho caminha em três direções clínicas: desenvolver uma clínica da cooperação, pela percepção de que os participantes fazem parte do mesmo coletivo de trabalho, potencializando a mobilização subjetiva e construindo regras coletivas de convivência e de ofício; desenvolver uma clínica das patologias, em que se resgata nos sujeitos a reconstrução de sua história de adoecimento e/ou de violência exposta no trabalho, possibilitando pensar o futuro do trabalho e de saúde dentro de uma perspectiva preventiva e com ganhos em recursos coletivos para enfrentar a doença; uma clínica da Inclusão, cujo foco está no esforço constituinte de sujeitos em situação futura de não trabalho (aposentados e desempregados).

Clínicas direcionadas a promover a análise do desejo (falta), do coletivo (demanda), por meio do discurso coletivo mobilizado para a mudança, subsumindo a mera execução de tarefas numa outra forma de zelo. Os que participam de uma atividade deôntica na vida do coletivo contribuem à cooperação, à organização do trabalho, às instituições e até mesmo à sociedade ${ }^{36}$. Nada muito diferente ao que busca e persegue a luta reformista por transformações na realidade de vida dos brasileiros e nos cenários de práticas assistenciais que se perseguem para o sistema de saúde.

\section{Considerações finais}

O trabalho em saúde interessa a este estudo enquanto um espaço altamente subjetivo em que se coagulam vários e contraditórios modos de fazer acontecer e realizar o saber-fazer, material e imaterial, de cada trabalhador singular, produtores e agentes de um setor econômico que se submetem a um modo de organização que busca uniformidade em seus processos de controle e regulação, mas que varia conforme os interesses econômicos, ideológicos e políticos daqueles que dominam o processo produtivo.

O trabalho em saúde está aberto à revolução copernicana na formação da força de trabalho, na remodelagem das práticas e da gestão de sistemas e de serviços de saúde, centrada em núcleos tecnológicos não dependentes de equipamentos, na produção do encontro dos trabalhadores e usuários. Para marcar uma mudança significativa na saúde pública, a análise e a intervenção nesse campo passa a exigir o reconhecimento da subjetividade desse trabalhador, ao afirmar que os profissionais da saúde participam da construção de saberes e disciplinas do seu campo e também influenciam as políticas em sua formulação e implementação, atuando na estruturação do mercado da doença.

Identifica-se uma fecunda afinidade entre o pensar da psicodinâmica e dos processos de trabalho e os modelos propostos mais recentemente em saúde, onde a participação do trabalhador é convocada na dinâmica de uma gestão compartilhada, o que o desafia a ser criativo e autônomo. Não fosse bastante, ainda há a ética particular como sua marca transcendente: um compromisso ético político em defesa da vida individual e coletiva. Valor de uso do trabalho em saúde plasmado pela relação e pelo compromisso efetivo dos trabalhadores com as necessidades dos usuários. Os processos de trabalho em saúde exigem, pois, que se vá além das normas e regras. Ao reconhecer presentes as especificidades do ser sob cuidado, estabelece e dá visibilidade às necessidades do ser cuidador, de quem se 
exige competências técnicas, engenhosidade e compromisso, enquanto apenas assinala uma retribuição moral/simbólica dada como compensação por sua contribuição à eficácia da organização do trabalho.

Diante da necessidade de que se desenvolvam os potenciais profissionais para que assumam as responsabilidades que lhes são atribuídas, a psicodinâmica do trabalho se revela uma vertente fecunda a ser explorada em estudos e investigações que se afiliem ao arcabouço lógico dos prazeres e reconhecimentos positivos que $o$ agir em saúde vem produzindo.

Precisa-se desenvolver, portanto, uma política convergente que integre o trabalhador da saúde, de modo que ao fortalecimento das ações em sua qualidade e resolutividade corresponda um indivíduo saudável, preparado psiquicamente para o enfrentamento da tarefa e das necessidades de saúde das pessoas em suas subjetividades. Isto é, é preciso ouvir suas demandas!

Com que armas e bagagens se pode influenciar e intervir na construção desse objetivo, considerando a saúde integral dos sujeitos construtores? Que seja crucial considerar o trabalhador da saúde como elemento potencializador de demandas coletivas que deverão mobilizar a gestão do trabalho a ir além da tríade eficiência/eficácia/efetividade proposta pelas lentes funcionalistas e economicistas da administração de serviços e de pessoal.

Importa cuidar da saúde de quem cuida da saúde, abrindo espaços dialógicos entre a gestão e o trabalho, para que sejam traduzidas as demandas psicodinâmicas do trabalho num pacto de convergência entre resultados e expectativas, voltado para o desenvolvimento individual e coletivo de cada contexto. Para que o trabalho tematize os tópicos do sofrimento e do prazer, assinalados a importância e o reconhecimento individual e coletivo dos envolvidos. Para permitir o feedback do sentimento de realização de si mesmo por parte do trabalhador e mobilização de ambos - gestores e trabalhadores - para novos compromissos, conhecimentos e cuidados.

\section{Colaboradores}

Aciole GG (0000-0002-6400-8293)* contribuiu para a concepção, o planejamento, a análise e a interpretação dos dados, orientou a elaboração do artigo e foi responsável pela revisão final do manuscrito. Pedro MJ (00000001-7960-3725)* contribuiu para a concepção, o planejamento, a análise e a interpretação dos dados; revisão crítica do conteúdo; e aprovação da versão final do manuscrito. 


\section{Referências}

1. Marx K. O Capital: crítica da economia política. 22. ed. Rio de Janeiro: Civilização Brasileira; 2004. Livro 1.v. 1.

2. Merhy EE. Saúde: a cartografia do trabalho vivo em saúde. São Paulo: Hucitec; 2002.

3. Pires D. Reestruturação Produtiva e Trabalho em Saúde no Brasil. São Paulo: Annablume; 1998.

4. Peduzzi M. Equipe Multiprofissional de Saúde: conceito e tipologia. Rev. Saúde Pública. 2001; Jan; 35(1):103-9.

5. Foucault M. O Nascimento da Clínica. 4. ed. Rio de Janeiro: Forense Universitária; 1994.

6. Aciole GG. Algumas considerações para o debate do controle social no SUS. Saúde debate. 2003; 27(63):63-73.

7. Aciole GG. A Saúde no Brasil: cartografias do público e do privado. São Paulo: Hucitec; 2006.

8. Ayres JRCM. Organização das Ações de Atenção à Saúde: modelos e práticas. Saúde Soc. 2009; 18(2):11-23.

9. Campos GWS. Subjetividade e administração de pessoal: considerações sobre modos de gerenciar o trabalho de equipes de saúde. In: Merhy EE, Onocko R, organizadores. Agir em saúde: um desafio para o público. São Paulo: Hucitec; 1997. p. 229-266.

10. Merhy EE. O SUS e um dos seus dilemas: mudar a gestão e a lógica do processo de trabalho em saúde (um ensaio sobre a micropolítica do trabalho vivo). In: Fleury S, organizadora. Saúde e Democracia - A luta do Cebes. São Paulo: Lemos; 1997. p. 125-143.

11. Weber M. A ética protestante e o espírito do capitalismo. São Paulo: Companhia das Letras; 2004.

12. Lovy M. Sobre o conceito de "afinidade eletiva" em Max Weber. PLURAL. 2011; 17(2):129-143.

13. Mendes-Gonçalves RB. Tecnologia e Organização Social das Práticas de Saúde. São Paulo: Hucitec; 1994.
14. Cunha GT. A construção da Clínica Ampliada na Atenção Básica. São Paulo: Hucitec; 2005.

15. Aciole GG. Falta um pacto na Saúde: elementos para a construção de um Pacto Ético-Político entre gestores e trabalhadores do SUS. Saúde debate. 2012; 36(95):684-694.

16. Franco TB, Bueno WS, Merhy EE. O acolhimento e os processos de trabalho em saúde: o caso de Betim. Minas Gerais, Brasil. Cad. Saúde Pública. 1999; 15(2):345-353.

17. Merhy EE. O Ato de Cuidar: a Alma dos Serviços de Saúde. In: Brasil. Ministério da Saúde. Departamento de Gestão da Educação na Saúde. Ver - SUS Brasil: cadernos de textos. Brasília, DF: Ministério do Trabalho; 2004. p. 108-137. (Série B. Textos Básicos de Saúde).

18. Mattos RA. A Integralidade na Prática (ou sobre a prática da Integralidade). Cad. Saúde Pública. 2004; 20(5):1411-1416.

19. Ayres JRCM. O cuidado, os modos de ser (do) humano e as práticas de saúde. Saúde Soc. 2004; 15(3):16-29.

20. Ceccin RB. Educação Permanente em Saúde: desafio ambicioso e necessário. Interface (Botucatu). 2005; 9(16):161-177.

21. Campos GWS. Um Método para Análise e Co-Gestão de Coletivos. 2. ed. São Paulo: Hucitec; 2005.

22. Campos GWS. O anti-Taylor: sobre a invenção de um método para co-governar instituições de saúde produzindo liberdade e compromisso. Cad. Saúde Pública. 1988; 14(4):863-870.

23. Fleury S. Desigualdades Injustas: O Contra direito à Saúde. Psicologia Soc. 2011; 23(supl):45-52.

24. Costa D, Lacaz FAC, Jackson Filho JM, et al. Saúde do Trabalhador no SUS: desafios para uma política pública. Rev. Bras. Saúde Ocup. 2013; 38(127):11-30. 
25. Brasil. Ministério da Saúde. Conselho Nacional da Saúde. Portaria 1823/2012. Institui a Política Nacional de Saúde do trabalhador e da trabalhadora. [internet] [acesso em 2015 nov 9]. Disponível em: http://conselho.saude.gov.br/web_4cnst/docs/Portaria_1823_12_ institui_politica.pdf.

26. Dejours C. Da psicopatologia à psicodinâmica do trabalho. In: Lancman S, Snelwar LI, organizadores. Christophe Dejours: Da psicopatologia à psicodinâmica do trabalho. Rio de Janeiro: Fundação Oswaldo Cruz. 2004. p. 47-104.

27. Mendes AM. Da Psicodinâmica à Psicopatologia do Trabalho. In: Mendes AM, organizador. Psicodinâmica do trabalho: teoria método e pesquisa. Diálogos em Psicodinâmica do Trabalho. São Paulo: Casa do Psicólogo; 2007. p. 29-48.

28. Ushida S. Organização do Trabalho: vivências de sofrimento e prazer. In: Mendes AM, Lima SCC, Facas EP, organizadores. Diálogos em Psicodinâmica do Trabalho. São Paulo: Paralelo 15; 2007. p. 105-118.

29. Mendes AM. Aspectos psicodinâmicos da relação homem-trabalho: Contribuições de C. Dejours. Psicolog. Ciênc. Profissão. 1995; 15(1-3):34-38.

30. Dejours C. O Fator humano. Rio de Janeiro: FGV; 2002.

31. Merlo ARC. Psicodinâmica do Trabalho. In: Jacques MC, Codo W, organizadores. Saúde mental \& trabalho: leituras. Petrópolis: Vozes; 2002. p. 130-142.
32. Peduzzi M, Schraiber LB. Processo de Trabalho em Saúde. In: Dicionário da Educação Profissional em Saúde. Rio de Janeiro: Fiocruz/MS [internet]; 2006. p.199-207 [acesso em 2015 nov 9]. Disponível em: http://www.sites.epsjv.fiocruz.br/dicionario/verbetes/protrasau.html.

33. Anjos FB, Mendes AM, Santos AV, et al. Trabalho Prescrito, Real e Estratégias de Mediação do Sofrimento de Jornalistas de um Órgão Público. Rev. Eletr. Sist. \& Gestão. [internet]. 2011; 6:562-582. [acesso em 2015 nov 9]. Disponível em: http://www.revistasg.uff.br/ index.php/sg/article/view/V6N4All/V6N4All.

34. Dejours C. A Sublimação, entre Sofrimento e Prazer no Trabalho. Rev. Port. de Psicanálise. 2013; 33(2):9-28.

35. Dejours C. Psicodinamica do Trabalho e Teoria da Sedução. Psicol. Estud. 2012; 17(3):363-371.

36. Machado AG, Merlo ARC. Cuidadores: seus amores e suas dores. Psicologia. \& Soci. 2008; 20(3):444-452.

37. Martins SR, Mendes AM. Espaço Coletivo de Discussão: A Clínica Psicodinâmica do Trabalho como Ação de Resistência. Rev. Psicol. Organ. Trab. 2012; 12(2):171-184.

Recebido em 06/06/2018 Aprovado em 22/01/2019 Conflito de interesses: inexistente

Suporte financeiro: não houve 